\title{
Contato, epidemias e corpo como agentes de transformação: um estudo sobre a AIDS entre os Índios Xokléng de Santa Catarina, Brasil
}

\author{
Contact, epidemics, and the body as agents \\ of change: a study of AIDS among the Xokléng \\ indians in the State of Santa Catarina, Brazil
}

Flávio Braune Wiik 1,2

\footnotetext{
1 Department of Anthropology, University of Chicago. 1126 East 59 $9^{\text {th }}$ Street, Chicago, IL 60637, USA. 2 Instituto de Estudos da Religião. Ladeira da Glória 98, Rio de Janeiro, $R J$ 22211-120, Brasil.
}

\begin{abstract}
Based on an analysis of AIDS cases among the Xokléng Indians in 1988, this article relates the illness phenomenon to socio-cultural disruptions and transformations in this indigenous group's universe, focusing on the history of their contact with Brazilian national society. The analysis and interpretation of this relationship are based on anthropological theories about the centrality of the body, corporeality, and degenerative bodily processes in Brazilian indigenous societies, according to which the body, society, and macro-situational elements are articulated by social praxis, and should thus be related in socio-anthropological studies of health-illness phenomena. The article briefly describes the history of epidemics emerging from contact and attempts to relate them to specific historical contexts. Ethnomedical categories, cosmology, and Xokléng concepts of corporeality are related to their social organization, which are thus connected to the AIDS cases. The latter are presented with a special focus on the relationship between their emergence and the changes occurring in the Xokleng world with the construction of a dam bordering on their land.
\end{abstract}

Key words Social Change; Acquired Immunodeficiency Syndrome; Xokléng; South American Indians

Resumo A partir da análise dos episódios de AIDS que acometeram os Índios Xokléng em 1988, o presente artigo visa referir fenômenos de doença a rupturas e transformações socioculturais ocorridas nesse universo com base na história de contato com a sociedade abrangente. A interpretação e a análise da relação estabelecida são feitas à luz de teorias antropológicas acerca da centralidade que corpo, corporalidade e processos corporais degenerativos ocupam nas sociedades indigenas brasileiras. Propõe-se que corpo, sociedade e agentes macroconjunturais são articulados pela práxis; por isso, devem ser relacionados nos estudos socio-antropológicos concernentes aos fenômenos de doença. O artigo traz a descrição sucinta das epidemias advindas com o contato, tentando vinculá-las aos contextos históricos específicos que o marcaram. Categorias da etnomedicina, cosmologia e corporalidade Xokléng são associadas à organização social e aos casos de AIDS. Estes são apresentados tendo, como enfoque principal, a ligação estabelecida entre seu advento e as transformações no universo Xokléng em função da construção da Barragem Norte junto a sua Terra.

Palavras-chave Mudança Social; Síndrome de Imunodeficiência Adquirida; Xokléng; Índios Sul-Americanos 


\section{Introdução}

As representações que as pessoas têm a respeito do corpo, da corporalidade e de processos corporais degenerativos - tais como as doenças - estão imbuídas das experiências que adquirem no mundo em que interagem. Em virtude disso, corporalidade, sociedade e agentes externos macroconjunturais estão interligados, formando uma tríade. Para os Xokléng, as transformações socioculturais e as doenças epidêmicas por que têm passado, sobrepõem-se em sua história de contato - com a sociedade que os abrange e com a qual vêm interagindo. Para compreendermos a relação que estabelecem entre doença e transformação sócio-cultural, devemos primeiro investigar quais são as categorias cosmológicas, conceitos e práticas etnomédicas Xokléng, suas representações de corpo e corporalidade e de práxis social. É através desses conceitos e práticas cotidianas que os Xokléng articulam concomitantemente fatores que marcam a sua própria história do contato e as transformações pelas quais têm passado, mediadas pelo corpo, por processos corporais degenerativos e por intervenções terapêuticas.

Para elucidar a argumentação acima, a segunda parte do artigo abordará o advento e os desdobramentos da Acquired Immunological Deficiency Syndrome (AIDS) entre os Xokléng. As considerações a respeito da AIDS são analisadas à luz da etnomedicina e dos contextos sócio-históricos que têm marcado a sociedade e a cultura Xokléng, os quais serão tratados na primeira parte do artigo.

\section{Índios Xokléng da Terra Indígena Ibirama (TII): contato, epidemias e rupturas sócio-culturais}

Os Índios Xokléng autodenominam-se Laklanõ. Fazem parte do tronco lingüístico jê. Somam hoje cerca de novecentos indivíduos agrupados na Terra Indígena Brasileira (TII), local em que foram reunidos pelo Serviço de Proteção ao Índio (SPI) a partir de 1914. A TII está situada na região do alto vale do rio Itajaí, a cerca de $260 \mathrm{~km}$ a noroeste de Florianópolis, Santa Catarina, ocupando uma área de 14.156 hectares de clima subtropical. A unidade de cooperação e de produção dominante é a de família extensa. Os Xokléng sobrevivem da agricultura de subsistência e do extrativismo, de atividades como diaristas e comerciantes de madeira, além das pensões dos idosos e da filantropia.

Desde os anos cinqüenta, componentes de sua cultura e das formas de organização social têm sido justapostos e reformulados à luz do cristianismo - que foi introduzido entre eles por missionários da Igreja Pentecostal Assembléia de Deus - e, mais recentemente, nas mãos de uma liderança religiosa autóctone.

A versão do pentecostalismo Xokléng tem servido de base para a reorganização e reunificação da sociedade. A grande maioria dos Xokléng se declara “crente". Ser "crente" não se restringe a abstrações teológicas individuais a respeito da fé; “crer" e ser "crente" revela-se através do cumprimento de princípios e dogmas "crentes" que dão diretriz e valor às práticas coletivas cotidianas. Converter-se em "crente" é fenômeno coletivo, é congregar uma comunidade de "irmãos”. Ser "crente" é também categoria identitária e diferenciadora que o grupo estabelece em relação a outras sociedades.

Em meados dos anos setenta, cerca de dez por cento da área mais plana e de terras produtivas da TII onde habitavam os índios foi inundada em função da construção da Barragem Norte, a qual represou o Rio Hercílio - antigo Itajaí do Norte - que corta a TII. Como veremos ao longo do artigo, o impacto causado pela construção da barragem tem sido enorme para os Xokléng; apresentando repercussões sociais, culturais, econômicas, políticas, médicas e ambientais.

A depopulação dos Xokléng da TII é o fato mais marcante de sua história de contato com a sociedade envolvente. Primeiro, em razão dos massacres sofridos por parte dos "Bugreiros". Depois, com a "pacificação", as epidemias levaram-nos ao quase total extermínio. Entre 1914 e 1932, epidemias de gripe, sarampo e tifo reduziram a população em dois terços, ou seja, de 400 para 150 indivíduos (Henry 1941; Urban, 1985). Epidemias de sarampo, de tifo e de doenças sexualmente transmissíveis (DST) assolaram os Xokléng entre os anos trinta e cinqüenta (Ribeiro, 1986; Santos, 1973). Apesar de a população ter voltado a crescer dos anos cinqüenta para cá, doenças endêmicas associadas à pauperização da população - como a tuberculose e a desnutrição - continuam a fazer-se presentes.

O impacto provocado pelas epidemias também trouxe rupturas sócio-culturais (Ribeiro, 1986, 1991; Santos, 1973; Urban, 1985). As mortes em massa fizeram com que os sobreviventes se dispersassem pela floresta, interrompendo a execução do ritual de iniciação dos jovens e de cremação dos mortos, ambas centrais para a reprodução de sua sociedade. 


\section{Zug-Kongó: as doenças dos brancos inimigos}

As zug-kongó ou "doenças de branco/inimigo" - zug nomeia, ao mesmo tempo, "homem branco" e/ou "inimigo" e kongó designa estar doente ou doença - são as doenças epidêmicas surgidas após o contato, às quais estão atrelados vários agentes etiológicos externos.

Segundo um informante: "Logo depois da pacificação [entre 1915 e 1930] quando nós saímos do mato para o limpo, veio muita doença das cidades dos brancos pelo vento". Nesse período, atribuíram-se doenças e mortes também ao sal - desconhecido pelos Xokléng - e ao envenenamento da comida distribuída pelo SPI.

O convívio com os brancos trouxe as pepke, que são feridas e/ou "esquentamento" nos órgãos genitais. De acordo com os Xokléng, as pessoas pegavam esse tipo de doença porque as mulheres mantinham relações sexuais com os funcionários do SPI e com colonos da região, transmitindo-a para os homens Xokléng.

Nos anos quarenta chegou mais uma epidemia, a bengá - o verbo beng significa "derreter" -, ou sarampo, que matou a maior parte das crianças e jovens que freqüentavam as aulas de português na primeira escola instalada na TII.

Os missionários da Assembléia de Deus chegaram nos anos cinqüenta, convidados pelos Xokléng para curar uma criança desenganada, vitimada provavelmente por uma segunda epidemia de sarampo. Ali se instalaram em razão do mérito de bons "rezadores" secularizados, que identificaram "o demônio" e o "diabo" como agentes etiológicos desagregadores da saúde física e social.

Nos anos setenta e oitenta, junto com a construção da Barragem Norte, chegaram as epidemias de kuzulo-téie ("tosse-comprida"), a coqueluche e a kuzulo-jhondén ("tosse-feia"), a tuberculose. Em seguida chegou a AIDS. Neste período, conforme informação de funcionários da FUNAI (Fundação Nacional do Índio), vários prostíbulos foram instalados junto à TII. Também foram relatados inúmeros casos de gonorréia. Em 1988, os Xokléng tornaram-se o primeiro grupo indígena no Brasil de que se teve notícia a enfrentar os primeiros casos de HIV/AIDS.

Portanto, o vento que penetrou a área devastada pelos brancos para agrupá-los, a comida salgada e envenenada - que representa a impossibilidade de consumir alimentos providos por eles mesmos -, o sexo com os brancos, a escola, os demônios e a barragem são identificados como agentes etiológicos. Eles ajudam os Xokléng a objetificar e historificar os diferentes momentos e conjunturas do encontro entre eles e a sociedade envolvente.

\section{Doenças, corporalidade e transformações históricas}

Em sociedades como a dos Xokléng, em que o individualismo, o capitalismo e a biomedicina - ou medicina ocidental alopática - não são soberanos, a busca pela origem e por agentes etiológicos das doenças não se limita ao corpo enfermo. Nessas sociedades, à origem da desordem física individual associam-se também desordens e mudanças que estão ocorrendo no universo social, político e econômico em que se dão as relações sociais. Portanto, é através de modelos explicativos acerca da origem e da etiologia das doenças e das intervenções terapêuticas que se confere sentido e se tenta restabelecer a harmonia ante a desordem dos corpos físico e social.

Melatti (1979) e Seeger et al. (1987) chamam a atenção para o fato de que, nas sociedades indígenas jê, a (re)produção social dos indivíduos está intimamente relacionada a sua (re) produção física, "sendo o corpo o mediador dos elementos centrais da estrutura social destas sociedades. (...) O corpo não somente sustenta identidades e papeis sociais, mas é, ele mesmo, um instrumento de atividades e práticas que articulam significados sociais e cosmológicos" (Seeger et al., 1987:13).

Dada a centralidade do papel do corpo e das representações a respeito da corporalidade nestas sociedades, a doença objetificada através do corpo pode gerar rupturas sociais. Diante dos fenômenos de doença, os corpos ficam impossibilitados de interagir em seu universo social. Adoecidas, as pessoas deixam de cumprir seu papel sustentador e edificante da identidade coletiva, não exercendo atividades que geram a própria reprodução destas sociedades.

Turner (1995) - estudioso dos Índios (jê) Kayapó - propõe que as representações concernentes aos processos corporais e à corporalidade devam ser relacionadas às ideologias que fundamentam a práxis dos integrantes de uma sociedade. Somente então poderemos analisar e relacionar estas representações a outros aspectos constitutivos de seu universo.

A proposta de Turner abre a possibilidade de fazermos uma análise mais abrangente a respeito da centralidade do corpo e da corporalidade na constituição das sociedades indígenas brasileiras. Tentarei formular minha argumentação a partir de um esquema simplificado. 
O corpo é o sujeito executor da práxis; sem ele, esta não é realizada. O que orienta e qualifica a práxis são as ideologias. As ideologias formam-se pela ação de agentes históricos. Estes constróem as ideologias em diferentes épocas e situações, tendo sempre por parâmetro o mundo concreto, físico e social que os rodeia e com o qual interage e que, por sua vez, os faz (re)definir os modelos de práxis a serem seguidos. Portanto, as representações a respeito do corpo, da corporalidade e dos processos corporais degenerativos são subprodutos culturais gerados na práxis social, que é sustentada por uma (ou mais) ideologia(s), as quais se forma(m) a partir da relação dialética entre os agentes sociais e o mundo conjuntural e contextual envolvente.

Em virtude disso, as representações que as pessoas de determinada sociedade têm acerca do corpo, da corporalidade e de processos corporais decorrentes estão imbuídas das experiências e de um conjunto de idéias elaborados a partir da relação de proximidade com fatores externos concretos, tais como: contato com a sociedade envolvente, aglutinação em áreas reservadas, epidemias, novas políticas introduzidas pela FUNAI, construção de barragens em Terras Indígenas, invasão de terras, exploração de recursos naturais e, por fim, monetarização e mercantilização das relações sociais. Isto faz com que corporalidade e estados corporais degenerativos, sociedade - através de seus agentes sociais - e agentes externos macroconjunturais formem uma tríade interligada. Elas devem sempre ser relacionadas nas análises sócio-antropológicas concernentes a fenômenos de doença, pois é a partir da práxis gerada em resposta aos fenômenos de doença materializados no corpo enfermo que se dá o processo de objetificação e de incorporação dos elementos externos macroconjunturais, os quais, por sua vez, são depositados pelos agentes sociais em construções culturais a respeito da corporalidade, do corpo e de processos corporais degenerativos.

Segundo os Xokléng, as transformações sócio-culturais e as epidemias por que têm passado, apresentam origem explicativa comum, cravada em sua história de contato com os zug. Por isso, os Xokléng associam a origem de doenças e mortes a agentes que marcam o contato. O elo de ligação entre os dois fatores etiológicos deve ser procurado nas categorias etnomédicas Xokléng, nas interpretações relativas à origem e etiologia das doenças, nas práticas terapêuticas, nas representações de corpo e corporalidade e no papel moral operado por sua versão do cristianismo. Através destes con- ceitos, os Xokléng constróem a sua própria história do contato, marcadas, por exemplo, pela invasão de seus territórios e pelo confinamento em uma "reserva", pela cristianização e pela construção da Barragem Norte.

\section{Elementos do universo etnomédico Xokléng}

Dois elementos da cosmologia Xokléng são centrais em seu sistema interpretativo no que diz respeito à origem de doenças, a mortes e a reveses: kuplen e ngayun.

Kuplen é o "duplo" que todas as pessoas, animais, plantas e elementos da natureza possuem. Kuplen confere-lhes vida e vontade. $K u$ plen e corpo físico formam um todo integrado e uno. Com a chegada do cristianismo, kuplen tem sido traduzido como "alma" ou "espírito". Ngayun são seres de forma semi humana - ou "monstruosa" - que habitam o universo. Por intermédio de possessão, assumem formas humanas ou de animais. A eles são atribuídos acontecimentos ruins, reveses e comportamentos humanos desviantes. Os evangélicos traduziram ngayun como "demônio" ou "diabo".

Os Xokléng associam o estado de doença à perda temporária do kuplen, que é aprisionado por um ngayun. A perda definitiva do kuplen devorado pelo ngayun - leva a pessoa à morte (Henry, 1941). O ngayun provoca o mal, agindo de várias maneiras. Ao incorporar-se a uma pessoa ou animal, ele seduz a vítima, convidando-a para comer a sua comida ou a ter relações sexuais. Ao aceitar, a vítima o incorpora ou a sua substância -, o que provocará doenças e morte. O ngayun, em sua forma monstruosa, devora a vítima, arrancando-lhe as entranhas pelo ânus. Os ataques do ngayun podem acontecer a qualquer momento em que a pessoa esteja acordada ou através de sonhos.

Notemos que o mal surge a partir de trocas ilícitas de intimidade, de fluidos corporais ou de ingestão de substâncias de procedência desconhecida ou ilícita. Associado a este fato, os Xokléng fazem analogia entre comer alimentos e "comer" uma pessoa, no sentido sexual. Esta analogia desvenda uma complexa teia que define idealmente preceitos e práticas reguladores a respeito das formas lícitas e ilícitas de partilha de substâncias entre os corpos, as quais estabelecerão as fronteiras entre as pessoas que podem ou não instituir alianças, ser ou não incorporadas a sua sociedade. Estes princípios refletem-se nas formas de organização social, parentesco e ocupação geofísica dentro da TII. 
A prática curativa xamânica era primordialmente a de extrair os elementos/seres (ngayun) do corpo do doente que estão devorando o seu kuplen (Henry, 1941). Com a participação dos parentes, eles eram extraídos por sucção, acompanhada de cantos rituais, enunciação de palavras em tons de voz alterados e por gestos rituais. Na atualidade, os pastores Xokléng mantiveram a estrutura da prática xamânica. Os pastores expurgam o ngayun (“diabo”) que está no corpo da pessoa, causando-lhe o mal ou fazendo com que sua vítima tenha comportamentos desviantes em relação aos padrões ideais "crentes". Durante os cultos recorrem a um tipo de linguagem ritual de tom dramático. Entre gritos e com a ajuda da comunidade reunida, possuída pelo espírito (kuplen) de Jesus, travam uma luta contra os "espíritos do mal". Ao expulsá-lo, a pessoa alcança a cura, que é testemunhada diante de todos após a sua reintegração à comunidade de "crentes".

A feitiçaria é outro agente causador de doenças, reveses e morte da dinâmica sócio-médica dos Xokléng. Os kuiä (feiticeiros) enviam feitiços ou para vingar-se de pessoas que lhes causaram mal, ou a mando de outras pessoas que querem vingar-se de algum mal causado por alguém identificado. A pessoa enfeitiçada, assim como a que está possuída pelo ngayun, sofre doenças, reveses e comporta-se estranhamente. O verbo "enfeitiçar", txê, é o mesmo para "amarrar" ou "atar" alguém. Há poucos kuiä entre os Xokléng; os mais procurados estão nas cidades e em Terras Indígenas vizinhas. Os kuiä conversam com o ngayun, orientando-os para causar o mal. Contra o feitiço, procura-se outro kuiä ou pastor Xokléng para proteção, extração do objeto/ser/demônio que está causando o mal.

Quando não se consegue curar uma doença que se torna crônica, a pessoa vai definhando gradativamente e se transforma em uma kongó-jhondén (“doença-feia” ou “doente-feio”). Uma kongó-hjondén origina-se por ação do ngayun ou feitiço. Uma vez diagnosticada, dificilmente tem cura. A morte social é usualmente anunciada junto ao diagnóstico.

Por ocasião da morte de uma pessoa, é feito um culto especial. $\mathrm{O}$ morto é enterrado com a cabeça voltada para o poente e todos os seus pertences íntimos são enterrados com ele ou queimados. O kuplen do morto é tido como muito "solitário" e "ciumento"; por isso, logo após deixar o corpo, quer companhia. Para evitar que ele queira "levar" consigo mais alguém, faz-se vigília na casa dos parentes do morto para seu kuplen seguir caminho sozinho.

O perigo de o kuplen do morto levar consigo os parentes deve-se à noção de co-substan- cialidade que é estabelecida entre os membros da família extensa durante a vida. As pessoas que partilham de intimidade sexual pela troca de fluidos corporais e as "que comem da mesma comida preparada no mesmo fogo e nas mesmas panelas" compartilham das mesmas substâncias físicas. Portanto, a unidade fisiológica não se restringe a indivíduos particulares, mas sim a uma comunidade de pessoas que derivam da mesma substância - uma construção cultural que viabiliza a incorporação dos afins aos consangüíneos na sociedade Xokléng. Em decorrência dessa crença, todos os que compartilham da mesma substância estão em perigo diante da morte e das doenças. Isto os leva tanto a cuidar quanto a isolar os doentes (graves) do convívio social. É por esse motivo também que, ao morrer o marido, a viúva é retirada temporariamente do convívio social. Durante este período, ela segue dieta alimentar diferente da usual e comum aos parentes, alimentando-se em recipientes separados. Sua comida é preparada em fogo próprio. Após alguns dias, ela é reintegrada à sociedade por meio de um ritual de agregação. Observa-se, nos dois casos, a ruptura temporária da cosubstancialidade dos parentes com o doente e com o morto. A co-substancialidade compartida por membros das unidades de família extensa reflete-se na proximidade de suas casas, que formam unidades sócio-políticas e econômicas em cada vila.

Os Xokléng usam ervas, emplastros e massagens para reverter sintomas físicos. Também são usuários e crêem na eficácia dos medicamentos alopáticos e dos serviços de orientação biomédica. No entanto, os modelos explicativos biomédicos a respeito da origem e etiologia das doenças crônico-degenerativas (kongójhondén) e causa mortis tornam-se secundários ou vazios de significado à luz do sistema interpretativo etnomédico que possuem. Nestes casos, o sistema autóctone é o mais significante, pois estabelece a origem e a etiologia dos episódios de doenças a partir de um repertoire que se amalgama à história da sociedade e a sua cultura. Por isso, "doença” só é substancializada com o surgimento de sintomas ou diante de comportamentos desviantes. "Doença” é deflagrada quando a pessoa se torna impossibilitada de interagir com a coletividade segundo princípios de (re)produção da sociedade tidos como "saudáveis" - por exemplo, manter a união e a cooperação restrita à família extensa, escutar os mais velhos, não "desviar" da religião, entre outros.

Ademais, a sua etnomedicina localiza o mal, relacionando-o aos conflitos sociais, políticos 
e econômicos e nas mudanças que ocorrem em sua sociedade. Os agentes patológicos sociais estão intimamente ligados aos motivos pelos quais os corpos adoecem. Segundo a etnomedicina Xokléng, não há descontinuidade estanque entre corpo individual e corpo social nem independência ontológica entre fatores internos e externos que os atingem.

\section{"Foi a barragem que trouxe a tal da AIDS pra cá"}

Os dados acerca dos primeiros casos de HIV/ AIDS entre os Xokléng foram coletados durante minha pesquisa-de-campo entre os anos de 1997 e 1998. Baseiam-se em entrevistas com informantes-chave - em particular, com uma agente indígena de saúde que cuidou dos doentes na época -, em entrevistas com funcionários da FUNAI regional de Curitiba, Paraná, e através de relatórios de viagens obtidos junto a sede da FUNAI de Curitiba. Visando proteger a identidade das pessoas citadas, seus nomes foram alterados, tal como o da aldeia em que os casos de AIDS ocorreram.

Com a elevação do leito do rio provocada pela barragem, houve grandes fissões políticas na sociedade Xokléng em razão de disputas pelo direito à exploração da madeira. Duas facções políticas romperam e duas famílias extensas deixaram a aldeia Sede para fundar a aldeia Cutia. Antônio provinha de um pequeno subgrupo Xokléng que vive nos arredores das cidades de Matos Costa e Calmon, a oeste de Santa Catarina. Ele e sua família migraram para a aldeia Cutia durante o boom da madeira no início dos anos oitenta. Antônio conheceu Joana em um dos muitos prostíbulos que proliferavam junto a Cutia como resultado do dinheiro obtido com o comércio da madeira. A certa altura, resolveram viver juntos e Antônio levou-a para morar em Cutia.

Joana foi levada para a Casa do Índio da FUNAI de Curitiba no início de 1988, após vários meses sentindo-se doente sem ser identificada a causa. De lá, foi encaminhada ao serviço médico público. O HIV foi logo detectado. Imediatamente, funcionários da FUNAI chamaram Antônio a Curitiba para ser submetido ao teste, que também teve resultado positivo. Joana morreu pouco tempo depois. Por sua vez, Antônio, sem qualquer sintoma - portanto, sem estar "doente" -, retornou a Cutia e levou vida normal.

Apesar de preocupados com o possível espalhamento do HIV entre os Xokléng, os funcionários da FUNAI não tomaram, de início, nenhuma medida profilática. Mas a informação da presença de AIDS entre os Xokléng vazou para a imprensa, a qual, da noite para o dia, invadiu a TII à procura do "índio que estava com AIDS”. Ao chegarem na TII com a notícia, os jornalistas assustaram os Xokléng. Primeiro, por não terem idéia formada a respeito da AIDS e, em segundo lugar, pela surpresa de que um deles estaria com tal doença. A imprensa tratou o assunto de acordo com um viés preconceituoso. Bastou a publicação das primeiras notícias para os Xokléng serem alvo de inúmeras acusações, ridicularizações e discriminações perante a sociedade nacional, seus vizinhos e outros grupos indígenas.

Somente quando se tornou pública a notícia, a FUNAI e autoridades de saúde do estado se deslocaram para a TII com o objetivo de fazer o levantamento dos comunicantes e informar a população a respeito da natureza da doença. Na época, conduziram um rastreamento das pessoas possivelmente expostas ao HIV por contato sexual com Antônio ou Joana e identificaram trinta e cinco pessoas (FUNAI, 1988). Ainda que amostras de sangue dessas pessoas tenham sido coletadas para a testagem sorológica anti-HIV - somente um teste do tipo ELISA foi feito - e este não tenha sido encontrado, tais dados nunca foram conclusivos ou divulgados pública e/ou oficialmente. Desde então, embora nenhum rastreamento epidemiológico haja sido feito novamente, suspeitase que outros casos tenham ocorrido com, pelo menos, mais uma morte associada aos primeiros casos de AIDS confirmada. Apesar da imprecisão dos dados epidemiológicos acerca da presença real do HIV/AIDS na população indígena do estado, acreditamos que não se possa falar ainda que atinja proporções epidêmicas.

A conjuntura sócio-política e econômica na época em que surgiram os casos de AIDS era delicada. Os Xokléng já estavam descapitalizados e com suas florestas totalmente devastadas. Havia fome, fissões familiares, falta de caça pelo desmatamento, abandono da agricultura, migração para a cidade, além de muitos casos de desnutrição infantil e tuberculose. Portanto, o rechaço que estavam sofrendo ao se verem ridicularizados por todos, somado à invasão de suas terras por centenas de jornalistas, médicos e pelo pessoal da FUNAI, associado à desinformação a respeito das formas de transmissão do HIV e, principalmente, em decorrência de experiências devastadoras anteriores com as epidemias trazidas pelos $z u g$, tudo isso fez com que o pânico e a fúria dominassem os Xokléng. Antônio sofreu ameaças de morte e sua família foi convidada a deixar a TII. 
A família de Antônio foi desestruturada. Seus pais se separaram. A mãe e irmãos mudaramse para uma favela de cidade industrial em Santa Catarina. Seu pai retornou à comunidade de origem.

Para os Xokléng, a “aids” (usamos aqui o termo em letras minúsculas como referência a um substantivo próprio cujo significado êmico independe da sigla AIDS, que designa um quadro sindrômico segundo a biomedicina) começava a ser definida como mais uma zug-kongó. Portanto, para ela convergiram a identificação de agentes etiológicos externos que os atingiram, o emprego de modelos explicativos para a origem da doença cravados na etnomedicina, cosmologia e religião Xokléng e a objetificação de elementos da macroconjuntura que marcava o contato à época. Cabe-nos agora tentar identificar a relação feita pelos índios entre esses três elementos.

Durante as palestras feitas sobre o HIV/ AIDS pela equipe da FUNAI na TII, vários vídeos foram mostrados, contendo as formas de prevenção e de transmissão do HIV, imagens de pacientes terminais e animações representativas da ação e forma do HIV.

A informação biomédica da existência de um vírus que causa a AIDS foi parcialmente aceita pelos Xokléng. Já que doença e sintomas são indissociáveis, eles rechaçaram a idéia de que um elemento invisível, que está dentro do corpo de alguém, possa permanecer por tempos sem provocar mal algum. Por outro lado, ao verem no vídeo o estado de saúde das pessoas que desenvolveram sintomas correlatos à AIDS e, principalmente, ao visualizarem o formato do HIV nos desenhos e fotos ampliadas, os Xokléng constataram que o que as pessoas da FUNAI chamavam de vírus era de fato um "bicho" ou um "monstro"; um "ngayun". A partir desse momento, os Xokléng começaram a estruturar um conceito acerca da doença com base em seus conceitos cosmológicos e etnomédicos.

No sistema etnomédico Xokléng, a idéia de um "bicho" que entra no corpo da pessoa, ou é enviado por alguém, e a destrói, comendo seu kuplen, é lugar comum. O que os Xokléng não crêem é na ausência de intencionalidade da pessoa que transmite o "bicho" para a outra e, muito menos, na idéia de que este bicho seja desprovido de "vontade". Eles acreditam que o "bicho que dá aids" faz com que as pessoas adquiram vontade de contaminar as outras, pois elas estão com (um elemento) ngayun no corpo, o que as faz tomar atitudes desviantes e/ou maléficas. Por isso, a pessoa com o vírus inspira cuidado e rechaço social.
A classificação da AIDS como uma DST fez sentido para os Xokléng. As DST fazem parte das zug-kongó, uma pepke. Como a pepke, a AIDS também chegou aos Xokléng via contato sexual com os brancos. Ademais, a possibilidade de uma pessoa passar esse "bicho" para a outra por contato sexual é coerente, pois o ngayun ou substâncias que dele provêm, podem entrar pelos órgãos genitais ou ânus das vítimas. Esta construção cultural facilita o incentivo ao uso do preservativo, pois este evita a troca de fluídos corporais durante o ato sexual. No entanto, o preservativo não livra totalmente a pessoa de contraí-lo, uma vez que, como agente etiológico de pepke, ele pode ser transmitido pela simples presença do "calor" dos corpos durante o ato sexual. O seu uso pode também restringir-se às relações sexuais que os Xokléng mantém com os zug. Mais ainda, é difícil incentivar o uso de preservativos em uma sociedade marcada pela depopulação e que tem na reprodução a maneira de perpetuar a sua existência.

As imagens dos pacientes terminais que foram mostrados nos vídeos fez com que os Xokléng relembrassem os sintomas e a decrepitude física de Joana. Segundo a agente indígena de saúde que cuidou de Joana, "ela tava muito magra, tinha perdido o cabelo, tinha febre, não podia andar. Tudo que ela comia fazia mal". Os médicos não chegavam a diagnóstico e ministravam remédios que não surtiam efeito. Então, o que a Joana tinha dentro de seu corpo era o "bicho da aids". As explicações de que a pessoa com AIDS pode ficar doente por muito tempo sem responder às intervenções terapêuticas, como no caso de Joana, levou os Xokléng a classificar a "aids" em uma kongó-jhondén. Desde os primeiros casos de AIDS na comunidade, as pessoas que morreram com kongójhondén, cujos sintomas relembrem os sofridos por Joana, são alvo de fofocas de que estavam com "o bicho da aids". As pessoas com uma kongó-jhondén como a "aids", apresentam sintomas que restringem sua participação em atividades diretamente atreladas aos processos de (re)produção da sociedade; por isso, pode causar rupturas sociais.

Por medo de continuarem compartilhando a mesma substância de Antônio, este sofreu várias sanções sociais. Seus parentes e amigos recusaram-se a tomar chimarrão na mesma cuia com ele, a beber cachaça no mesmo copo, a fazer refeições com ele. As mulheres não se aproximaram mais dele. Embora negasse que estivesse com "aids", um dia teve um desmaio. Os índios interpretaram como sinal de que ele estava mesmo com "a tal da aids" e não lhe foi 
mais permitido trabalhar ou desempenhar qualquer atividade em grupo. Antônio sentia-se fraco. Já convencido de que estava com “aids”, começou a desenvolver vários sintomas. Deixou a Cutia e foi para a casa da mãe na favela da cidade onde morava. Morreu pouco tempo depois, rejeitando ajuda biomédica.

O conceito de co-substancialidade e o risco de ter pego "aids", por ser uma pepke fizeram com que as pessoas próximas de Antônio e Joana receassem por sua própria contaminação. Principalmente após a equipe da FUNAI elaborar uma lista de pessoas que mantiveram contado sexual com eles, deflagrando vários adultérios, fez com que vários casais se separassem. Praticamente todos os moradores da Cutia queriam fazer o teste anti-HIV, o que foi descartado pela equipe de saúde. Dez anos após as trinta e cinco pessoas terem sido submetidas aos testes, perguntei à agente indígena de saúde se chegaram a saber o resultado. Ela me afirmou: “nunca ninguém voltou aqui pra dá o resultado. A gente acha que, de certo, ninguém tinha a tal da AIDS no corpo, porque se tivesse, eles vinha avisar e levar os índios para Curitiba".

É importante ressaltar que, após os primeiros casos de AIDS, houve um movimento de retorno à comunidade de crentes por parte de muitos Xokléng que estavam "desviados" - isto é, que tinham temporariamente deixado de seguir os preceitos da Assembléia de Deus, portanto estavam impossibilitados de "congregar" com a comunidade. Os pastores Xokléng relataram que já haviam tido premonição a respeito da epidemia de "aids". Para eles, esta era um sinal concreto do apocalipse que se aproximava. Usaram essa premonição para reagrupar o rebanho disperso pelo pecado advindo do dinheiro da venda da madeira após a construção da barragem e que se tinha concretizado através da "aids" entre eles. O retorno à comunidade de crentes envolve uma série de rituais de cura; dentre eles, o da expulsão do "bicho da aids" de dentro do corpo, o que envolve automaticamente a reconstituição das famílias, o abandono do álcool e o retorno à miséria socializada por todos. Cabe apontar que o retorno aos preceitos da comunidade de crentes ocorreu concomitantemente à desmonetarização da sociedade em razão do fim do comércio de madeira.

Como vimos, a "aids" como mais uma zugkongó traz também fatores macroconjunturais em sua origem e etiologia que evidenciam e temporalizam o contato entre os Xokléng e a sociedade envolvente. Neste nível macro, a barragem aparece nos relatos dos Xokléng como responsável pelo surgimento da doença entre eles em virtude de fatores físicos concretos tais como, represar o rio - e pelas conseqüências sociais perniciosas oriundas de sua construção. Como bem afirmou um Xokléng:

“A 'aids'[assim como outras doenças de características epidêmicas surgidas desde o início da construção da barragem] apareceu depois que a água do rio parou de correr e começou a subir (...) Aí o pessoal [os Xokléng] foi se mudando pra cima dos morro pra fugi das enchente. A gente perdeu tudo, casa, criação, roça, fruteira, tudo num dia. Aí o pessoal começou a tira madeira; de início, era só pra construir casa nova, despois só queria saber de tirar mais madeira e gastar o dinheiro com bebida, carro e com as mulher branca. As mulher [Xokléng] casada também deixou de seus marido pra segui os branco que ajudava a tira a madeira. Foi aí então que aquela uma [Ângela] chegou pra mora aqui e truxe a tal de 'aids' pra cá (...) Antes da barragem não tinha isso aqui não. As família morava tudo junto, perto da [aldeia] Sede, trabalhava junto na roça, caçava junto (...) As madeira foi acabando e aí é que eles se dividiu tudo atrás de mais madeira (...) a madeira acabou e a gente tá tudo morando espalhado, doente, com fome (...) Tô conversando com os parente a modo de nós explodir tudo a barragem e volta a mora junto perto do rio."

\section{Conclusão}

Dada a centralidade do papel do corpo, da corporalidade e dos processos corporais degenerativos na sociedade Xokléng, cremos que foram as experiências e a decorrente construção de modelos interpretativos etnomédicos acerca da "aids" que viabilizaram a internalização e a objetificação das radicais mudanças e rupturas sofridas em seu universo a partir da construção da barragem. Ao associarem a origem da "aids" à barragem, os Xokléng estão exercendo um raciocínio claramente empírico, cravado nos efeitos surtidos desde a sua construção, a exemplo de: entrada dos brancos trabalhadores da barragem, que mantinham relações sexuais com suas mulheres ou que se casavam para poder ter direito de explorar a madeira; brigas e fissões entre as famílias; entrada de dinheiro como mediador das relações sociais e sexuais; divisão da comunidade; fracionamento da TII em "frentes de exploração" para comercialização da madeira por famílias nucleares; e, por fim, abandono dos preceitos da Assembléia de Deus.

O fato de Antônio ter contraído "aids" por partilhar intimidade física com uma $z u g$, uma 
prostituta que se aproximou inicialmente dele por intermédio do dinheiro - um mediador de relações sociais pouco usuais no universo Xokléng até o boom da madeira, e que trouxe inúmeras rupturas ao seu universo - levou os índios à construção a posteriori de uma série de associações entre o advento do dinheiro e relações perniciosas e ilícitas advindas da mercantilização das relações sociais na TII. Com o fim do capital gerado pela comercialização da madeira e com a ajuda das pregações dos pastores Xokléng - que apelam a conceitos "tradicionais" a respeito da corporalidade e co-substancialidade - estas relações foram gradativamente voltando a ser intermediadas por laços de solidariedade e consangüinidade entre membros das famílias extensas; este processo foi dramatizado através de rituais de reconversão dos "desviados" à comunidade de "crentes".

A AIDS também se tornou uma metalinguagem contemporânea acerca dos conflitos históricos que têm marcado as relações entre índios e brancos na região. A reticência com que os Xokléng reportam os episódios da doença entre eles, mesmo dez anos tendo-se passado, origina-se na intolerância étnica que sofreram por parte dos colonos teuto-brasileiros vizinhos à TII na época. Segundo os colonos, a origem da AIDS entre os Xokléng está no "desperdício" e na "promiscuidade". Embora os grandes beneficiários com a venda da madeira da TII tenham sido os próprios comerciantes e políticos locais, o fato dos Xokléng terem acesso a parte do capital gerado pela sua comercialização "sem trabalhar" ou "sem pensar em poupar” representou verdadeiro acinte para uma sociedade de raízes luteranas, austera, parcimoniosa e trabalhadora. A AIDS foi usada como metáfora de uma ética errônea adotada pelos Índios, a qual, ao mesmo tempo, fortaleceu o modelo de vida adotado pelos brancos.

A construção local da "aids", assim como de outros fenômenos de doença de caráter epidêmico, mostrou-nos como os agentes sociais criam significados subjetivos e específicos para uma pandemia, ao transformá-la a partir do que vêem e experimentam dos casos particula- res da doença. Portanto, a universalidade patológica da AIDS ou de outras doenças epidêmicas é alterada e relativizada por intermédio de processos sociais dialéticos de incorporação e externalização da experiência coletiva dos fenômenos da doença com um todo.

O processo da criação de um modelo explicativo para a origem da AIDS, que engloba tanto elementos presentes na cosmovisão e na etnomedicina Xokléng quanto elementos macroconjunturais - como uma barragem e o dinheiro evidenciam mudanças concretas que ocorreram na sociedade junto ao advento da AIDS; esta tornou-se epifenômeno dessas transformações.

Através de processos políticos em que se contrapõem, se rechaçam e se incorporam novas ideologias - como as surgidas com o capital gerado pelo comércio da madeira a partir da construção da barragem -, as pessoas começam a agir de forma diferente, naturalizando as inovações sociais e econômicas. Foram estas inovações ideológicas que reformularam temporariamente a práxis Xokléng - e, em decorrência, a sua organização socioeconômica - tal como foram estas inovações que, aos olhos dos Xokléng, trouxeram a "aids" até eles. Foram também estas as inovações que rechaçaram ao se descapitalizarem, ao constatarem que ela ameaçava tanto sua existência física quanto sua reprodução social pelo papel central ocupado pelo corpo e corporalidade em sua sociedade. A resposta foi um retorno ao "tradicionalismo”, um retorno à comunidade de crentes, espaço em que detêm o domínio das formas de interação, intermediação e práticas sociais.

Por último, é importante ressaltar que este processo foi mediado pelo corpo enfermo e por subseqüentes respostas práticas de intervenções terapêuticas religiosas, bem como por representações autóctones a respeito da corporalidade, os quais, por sua vez, aparecem relacionados a contextos socioeconômicos, históricos e médicos específicos, uma vez que, em sociedades como a dos Xokléng, corpo, sociedade e agentes macroconjunturais externos são intimamente interligados e assim devem ser estudados. 


\section{Referências}

FUNAI (Fundação Nacional do Índio), 1988. Relatório de Viagem. Curitiba: Superintendência Executiva Regional, FUNAI.

HENRY, J., 1941. Jungle People: a Kaingang Tribe of the Highland of Brazil. Richmond: William Byrd Press Inc.

MELATTI, J., 1979. The relationship system of the Krahó. In: Dialectical Societies, the Gê and Bororo of Central Brazil (D. Maybury-Lewis, ed.), pp. 4682, Cambridge: Harvard University Press.

RIBEIRO, D., 1986. Os Índios e a Civilização: a Integração das Populações Indígenas no Brasil Moderno. 3a Ed. Petrópolis: Editora Vozes.

RIBEIRO, D., 1991. A pacificação dos Xokléng. In: Revista Carta: Falas, Reflexões, Memórias (D. Ribeiro, org.), pp. 15-32, Brasília: Impressão Gráfica do Senado Federal.
SANTOS, S. C., 1973. Índios e Brancos no Sul do Brasil: a Dramática Experiência dos Xokléng. Porto Alegre: Editora Movimento.

SEEGER, A.; DA MATTA, R. \& VIVEIROS-DE-CASTRO, E. B., 1987. A construção da pessoa nas sociedades indígenas brasileiras. In: Sociedades Indígenas e Indigenismo no Brasil (J. P. Oliveira Filho, org.), pp. 11-30, Rio de Janeiro: Editora Marco Zero, Universidade Federal do Rio de Janeiro.

TURNER, T., 1995. Social body and embodied subject: Bodiliness, subjectivity, and sociality among the Kayapó. Cultural Anthropology, 10:143-170.

URBAN, G., 1985. Interpretation of inter-cultural contact: The Shokleng and Brazilian national society 1914-1916. Ethnohistory, 32:224-244.

WIIK, F. B., 1998. Doenças e transformação sociocultural: Epidemias, corporalidade e práxis entre os Índios Xokléng do sul do Brasil. Revista de Divulgação Cultural, 64:59-67. 